\title{
Meninjau Aspek Kinerja Sistem Informasi Akuntansi Pada Badan Layanan Umum Daerah (BLUD) Rumah Sakit Umum (RSU) Jampang Kulon
}

Affiliation:

Universitas Muhammadiyah Sukabumi

*Correspondence:

dikdikteja07@gmail.com

This Article is Avalilable in:

https://journal.umy.ac.id/index.

php/jati/article/view/8125

DOI:

10.18196/jati.030124

\section{Citation:}

Teja Lesmana, D. (2020). Analisis Faktor-Faktor Yang Mempengaruhi Kinerja Sistem Informasi Akuntansi Pada Badan Layanan Umum Daerah (BLUD) Rumah Sakit Umum (RSU)

Jampangkulon. Jati: Jurnal Akuntansi Terapan Indonesia, 3(1), 29-33.

\section{Article History}

Received:

03 February 2020

Reviewed:

04 March 2020

Revised :

11 March 2020

Accepted:

31 March 2020

Topic Article:

Sector Public Accounting

\author{
Dik Dik Teja Lesmana*1, Chofiuddin Muchlis², Rima Purwanti ${ }^{3}$
}

\begin{abstract}
:
The purpose of this study is to determine the factors that influence the performance of accounting information systems. The factors studied were information technology, top management support and human resource competencies at the Jampang Kulon General Hospital. The research model used is a qualitative method with data collection namely interviews, observation, and documentation. Data analysis techniques used are: 1) data collection, 2) data reduction, 3) data presentation, 4) inference and verification. The results showed that: 1) information technology was strongly supported in processing accounting data at Jampang Kulon Hospital so that the financial statements needed by users could be quickly obtained. 2) The involvement of top management plays a very important role in the development of information systems by providing the resources needed by the facility, so that the performance of the accounting information system produced is of very high quality and the performance of the Hospital will increase. 3) Competence of Human Resources who have the knowledge and skills in using information technology play an important role in supporting the performance of accounting information systems that are produced increasingly better.
\end{abstract}

Keywords: Information Technology, Top Management Support, Competence of Human Resources

\begin{abstract}
Abstrak:
Tujuan penelitian ini adalah untuk mengetahui faktor yang mempengaruhi kinerja sistem informasi akuntansi. Adapun faktor yang diteliti adalah teknologi informasi, dukungan manajemen puncak dan kompetensi sumber daya manusia di Rumah Sakit Umum Jampang Kulon. Model penelitian yang digunakan adalah metode kualitatif dengan pengumpulan data yaitu wawancara, observasi, dan dokumentasi. Teknik analisis data yang digunakan adalah: 1) Pengumpulan data, 2) reduksi data, 3) Penyajian data, 4) inferensi dan verifikasi. Hasil penelitian menunjukkan bahwa: 1) teknologi informasi sangat didukung dalam pengolahan data akuntansi di Rumah Sakit Jampang Kulon sehingga laporan keuangan yang dibutuhkan oleh pengguna dapat dengan cepat diperoleh .2) Keterlibatan manajemen puncak sangat berperan dalam pengembangan sistem informasi dengan menyediakan sumber daya yang dibutuhkan fasilitas, sehingga kinerja sistem informasi akuntansi yang dihasilkan berkualitas sangat tinggi dan kinerja Rumah Sakit akan meningkat. 3) Kompetensi Sumber Daya Manusia yang memiliki pengetahuan dan keterampilan dalam menggunakan teknologi informasi sangat berperan dalam mendukung kinerja sistem informasi akuntansi yang dihasilkan semakin baik.
\end{abstract}

Kata Kunci: Teknologi Informasi, Dukungan Manajemen Puncak, Kompetensi Sumber Daya Manusia 


\section{PENDAHULUAN}

Sistem Informasi Akuntansi (SIA) merupakan sekumpulan sumber daya dimana dirancang untuk mentransformasikan data menjadi informasi. Informasi ini kemudian dikomunikasikan kepada pemakai. Siklus-siklus pemrosesan transaksi, penggunaan teknologi informasi dan pengembangan sistem informasi ini dikenal dengan istilah sistem informasi pemakai. Krismiaji (2015: 4) menyatakan bahwa sistem informasi akuntansi merupakan sebuah sistem yang memproses data dan transaksi agar menghasilkan informasi yang bermanfaat untuk merencanakan, mengendalikan dan mengoperasikan bisnis. Sistem informasi akuntansi ini sangat bermanfaat untuk mencapai tujuan organisasi perusahaan yang keberhasilannya dipengaruhi oleh penggunaan sistem tersebut meningkat, kualitas sistem lebih baik dari sebelumnya, atau kepuasan pemakai informasi.

Perusahaan menjalankan aktivitas operasionalnya menggunakan sistem informasi akuntansi guna membantu dalam mencapai tujuan perusahaan. Rumah sakit juga menggunakan sistem informasi yang bertujuan untuk melayani masyarakat. Oleh karena itu, dibutuhkan informasi yang akurat dalam pengolahan data dan sistem pada rumah sakit agar mempermudah pelayanan terhadap masyarakat. Dari hal tersebut, maka dapat kita diketahui bahwasanya manajemen dari organisasi yang sudah dilaksanakan. Kinerja organisasi dapat dinilai melalui laporan keuangan yang baik dan lengkap untuk memberikan informasi yang bermanfaat bagi manajemen dalam pengambilan keputusan. Oleh karena itu, diperlukan sebuah sistem informasi akuntansi yang didukung oleh teknologi informasi yang terkomputerisasi. Jika kinerja sebuah organisasi ingin meningkat, maka harus didukung oleh kinerja sistem informasi yang baik, dan agar sebuah organisasi dapat mengahasilkan kinerja yang baik, begitu juga sebaliknya kinerja dari sebuah sistem informasi didukung oleh sistem informasi akuntansi yang terkomputerisasi. Namun dalam kenyataannya masih banyak perusahaan merasa kurang puas terhadap kinerja sistem informasi akuntansi yang dimiliki. Hal tersebut dikarenakan pemakai sistem informasi tidak mengerti dan memahami secara benar cara mengoperasikan sistem tersebut sehingga kinerja tidak memuaskan.

Keberhasilan suatu sistem informasi berkaitan erat terhadap kinerja yang dimiliki oleh sistem tersebut. Tolak ukur dalam menentukan baik buruknya sebuah kinerja sistem informasi adalah dengan melihat kepuasan dari pemakai sistem informasi akuntansi dan pemakaian dari sistem informasi akuntansi itu sendiri. Kepuasan dari pengguna sistem informasi akuntansi bisa dilihat dari seberapa jauh pengguna mempunyai perasaan senang dan percaya terhadap sistem informasi yang digunakan untuk menghasilkan informasi sesuai kebutuhannya (relevan), mengandung sedikit kesalahan (accurate), serta mampu menghasilkan informasi tepat waktu

(timelines), sedangkan pemakaian system informasi akuntansi tingkat keberhasilan diukur melalui sebuah sistem informasi apabila frekuensi penggunaannya sering maka dikatakan baik (Khaidir dan Susanti, 2015).

Baik buruknya kinerja sistem informasi akuntansi apabila informasi yang diterima memenuhi harapan pengguna informasi dan mampu memenuhi kepuasan bagi penggunanya. Kinerja dapat dipengaruhi oleh faktor-faktor yang meliputi kemampuan teknik personal sistem informasi, dukungan manajemen puncak, kepuasan pengguna akhir, keberadaan program dan pendidikan pemakai (Romney dan Steinbart, 2006: 249-252).

Berdasarkan hasil observasi peneliti di BLUD Rumah Sakit Umum Jampangkulon hambatan yang muncul dalam pelaksanaan sistem informasi berbasis teknologi informasi adalah keterbatasan keterampilan sumber daya manusia yang menyebabkan pencapaian pelaksanaan dan fungsinya dalam pelayanan terhadap masyarakat.

Selain itu, berdampak pada pelimpahan beban kerja dari pegawai satu ke pegawai yang lebih terampil. Oleh sebab itu, dibutuhkan penerapan teknologi informasi dimana seharusnya diimbangi dengan keterampilan sumber daya manusia yang mumpuni. 
Penelitian terhadap efektivitas atau keberhasilan kinerja sistem informasi akuntansi telah banyak dilakukan namun masih adanya permasalahan dan inkonsistensi dari hasil-hasil penelitian sebelumnya sehingga menjadi dasar bagi penelitian ini untuk menguji kembali dan menganalisis faktor-faktor yang mempengaruhi keberhasilan kinerja sistem informasi akuntansi.

\section{METODE PENELITIAN}

Objek penelitian adalah Rumah Sakit Umum (RSU) Jampangkulon. Metode yang digunakan dalam penelitian ini adalah metode kualitatif dengan pendekatan deskriptif menggunakan data primer dan sekunder. Metode penetapan sampel yang digunakan adalah purposive sampling. Peneliti akan menganalisis faktor-faktor yang mempengaruhi kinerja sistem informasi pada Rumah Sakit Umum(RSU) Jampangkulon.

\section{HASIL DAN PEMBAHASAN}

\section{Teknologi Informasi pada RSUD Jampangkulon}

Dari hasil penelitian di BLUD RSU Jampangkulon, di mulai dari bagian perangkat keras (hardware), pemakaian komputer digunakan sebagai salah satu media alat untuk pengolahan data, di rumah sakit jampangkulon sudah menggunakan komputer untuk melakukan pengolahan data keuangannya dan bagian bidang lainnya. Dengan menggunakan komputer membuat pekerjaan menjadi lebih cepat, akurat dan tepat hasilnya, daripada secara manual menggunakan laporan keuangan secara tertulis.

Dari bagian Software, dengan adanya sistem informasi akuntansi berbasis komputer mempermudah perhitungan serta memaksimalkan kinerja rumah sakit. Dengan adanya sistem informasi akuntansi, rumah sakit jampangkulon menyadari manfaat dari sistem informasi akuntansi berbasis komputer mampu meningkatkan kinerja rumah sakit, memaksimalkan pekerjaan, serta menghemat waktu bekerja secara sistematis. Program yang terintegrasi dengan beberapa computer ini membuat pegawai mudah untuk mengerjakannya.

Kemudian dari bagian brainware, Setiap bagian telah berperan dengan baik dalam menjalankan sistem informasi yang dijalankan oleh rumah sakit. Hal ini terbukti melalui hasil wawancara dengan narasumber, mayoritas telah berjalan dengan baik, koordinasi antar pegawai terjalin, dan kesadaran dalam menjalankan sistem informasi telah baik.

Berdasarkan pembahasan diatas bisa disimpulkan bahwa dengan adanya pemanfaatan teknologi informasi berbasis komputer pada Rumah Sakit Umum Jampangkulon dapat membantu para staf/ pegawai dalam melaksanakan tugasnya guna menghasilkan informasi yang akurat serta lebih cepat diperoleh. Selain itu dampak teknologi informasi bagi sistem informasi akuntansi dapat membantu mempermudah penerapan pelaksanaan sistem informasi akuntansi dan juga dapat membantu dalam meningkatkan kinerja instansi.

Hasil ini konsistensi dengan hasil penelitian sebelumnya yang dilakukan oleh dilakukan oleh A.A. Ngr. Yoga Krisna Aditya dan Ni Luh Sari Widhiyani (2017) menunjukan bahwa teknologi informasi berpengaruh pada sistem informasi akuntansi. Hasil penelitian ini didukung oleh teori Abdul Kadir (2014: 15) bahwa peran manusia dapat digantikan oleh teknologi informasi, serta teknologi informasi juga berperan dalam restrukturisasi terhadap peran manusia.

\section{Peran Manajemen Puncak Dalam Menunjang Kinerja SIA}

Manajemen puncak atau pimpinan memegang peranan penting terhadap tahapan siklus pengembangan dan keberhasilan implementasi sistem informasi. Dukungan manajemen puncak menurut Romney dan Steinbart (2006:64 merupakan bagaimana manajemen puncak mendefinisikan suatu informasi serta pemrosesan yang diperlukan, membuat tujuan sasaran sistem, melakukan review sistem dan mengalokasikan dana. Kesuksesan sistem informasi terhadap 
aktivitas perusahaan dipengaruhi oleh dukungan yang diberikan manajemen puncak terhadap sistem informasi akuntansi.

Salah satu indikator yang digunakan untuk mengukur tingkat keberhasilan kinerja sistem informasi akuntansi dalam suatu perusahaan adalah dukungan manajemen puncak. Apabila suatu kinerja sistem informasi akuntansi perusahaan buruk, diperlukan evaluasi untuk melihat apakah pemberian dukungan manajemen puncak oleh suatu perusahaan telah sesuai dengan karyawan atau tidak, dimana hal tersebut berdampak secara langsung pada penilaian kinerja sistem informasi akuntansi perusahaannya.

Dukungan manajemen yang baik maka mempengaruhi penilaian kinerja sistem informasi yang baik juga. Hasil penelitian tersebut diperkuat melalui kajian teori yang dikemukakan oleh Shield (1995) dalam Sahusilawane (2015) yang menyatakan bahwa dukungan manajemen puncak mempengaruhi keberhasilan implementasi sistem baru serta pengembangan daya inovatif bawahan. Sharma (2003) menyatakan bahwa dukungan terhadap tindakan yang dilakukan secara tidak langsung maupun simbolis oleh seorang manajer akan berkontribusi terhadap kesuksesan implementasi sistem informasi dengan memberikan motivasi kepada para pengguna sistem informasi.

\section{Peran Kompetensi Sumber Daya Manusia Terhadap Kualitas SIA}

Berdasarkan hasil penelitian bahwa sebagian karyawan yang ada di Rumah Sakit Umum Jampangkulon belum sesuai kualitas dan tanggungjawabnya. Hal tersebut dapat dilihat dari latar belakang pendidikan karyawan yang mana tidak semuanya lulusan sarjana. Pada bagian keuangan di rumah sakit umum jampangkulon mayoritas karyawan yang menjabat sudah sesuai dengan bidang ahlinya yang mana lulusan sarjana ekonomi/akuntansi. Apabila bagian akuntansi dijabat oleh seseorang yang tidak sesuai dengan bidang keahliannya makan akan memungkinkan terjadinya suatu kesalahan pembuatan laporan keuangan, ketidakpahaman mengenai tugas dan fungsinya, dan laporan keuangan yang tidak akurat. Hal tersebut akan berpengaruh buruk bagi perusahaan yang menginginkan untuk terus berkembang.

Berdasarkan hasil pembahasan mengenai kompetensi sumber daya manusia pada rumah sakit umum Jampangkulon yang di ukur menggunakan indikator pengetahuan, keterampilan dan sikap, dapat disimpulkan bahwa sumber daya manusia yang ada pada rumah sakit umum Jampangkulon mayoritas pegawai/karyawan sudah cukup berpengalaman dalam bekerja serta memiliki keahlian dibidang pekerjaannya masing-masing, khususnya pegawai/karyawan yang bekerja pada bidang akuntansi atau keuangan. Mayoritas pegawai yang lulusan sarjana latar pendidikannya telah sesuai dengan bidang pekerjaannya serta memiliki keterampilan menggunakan teknologi informasi untuk memproses data keuangan di rumah sakit yang berpengaruh terhadap kinerja sistem informasi yang dihasilkan. Keberhasilan suatu perusahaan atau instansi itu bukan hanya dipengaruhi oleh sumber daya manusia yang dimilikinya, namun juga kompetensi yang dimiliki oleh sumber daya manusianya.

Hasil penelitian ini didukung juga oleh teori Barry E. Cushing dan diterjemahkan oleh Ruchyat Kosasih (2007) bahwasanya sumber daya manusia suatu perusahaan dalam mengolah data akuntansi merupakan karyawan yang telah memiliki pengetahuan dan pengalaman cukup dibidangnya, sehingga dapat menunjang suatu sistem informasi akuntansi perusahaan. Hasil penelitian didukung oleh teori Mulyadi (2005) dimana karyawan yang jujur dan memiliki keahlian dibidang yang menjadi tanggungjawabnya akan melakukan pekerjaannya secara efektif dan efisien.

\section{KESIMPULAN}

Berdasarkan hasil penelitian maka dapat disimpulkan bahwa penggunaan teknologi informasi pada Rumah Sakit Umum Jampangkulon sangat mendukung bagi para staf/ pegawai 
dalam kualitasinformasi yang dihasilkan. Pengolahan data akuntansi dapat dilakukan dengan lebih cepat dengan menggunakan komputer. Selain itu, dengan sistemakuntansi yang terkomputerisasi laporan keuangan yang diperlukan oleh para pengguna dapat dengan cepat diperoleh.

Keterlibatan manajemen dalam implementasi dan pengembangan sistem dengan menyediakan fasilitas sumber daya yang dibutuhkan sangat berperan dalam menunjang sistem informasi akuntansi rumah sakit, dengan begitu kinerja dari rumah sakit akan semakin meningkat. Kompetensi sumber daya manusia memiliki peranan penting dalam kinerja sistem informasi akuntansi, dengan kualitas laporan keuangan yang dihasilkan dapat dipahami, relevan, dan andal (reliable).

\section{DAFTAR PUSTAKA}

Aditya, A.A. Ngr. Yoga Krisna. 2018. Pengaruh Kecanggihan Teknologi Pada Efektivitas SIA DenganDukungan Manajemen Puncak, Dan Kemampuan Teknik Personal Sebagai Pemoderasi. EJournal [Online], Vol. 23 No.1, 705-733. Tersedia: https://doi.org/10.24843/EJA. 2018.v23.i01.p27 [26 Juli 2019].

Almilia, Luciana Spica. 2007. Faktor-Faktor Yang Mempengaruhi Kinerja Sistem Informasi Akuntansi Pada Bank Umum Pemerintah Di Wilayah Surabaya Dan Sidoarjo.

Barry E.Cushing. 2007. Sistem Informasi Akuntansi dan Organisas. Perusahaan. Penerjemah Ruchyat Kosasih. Jakarta: Penerbit Erlangga Penerjemah.

Kadir, Abdul. 2014. Pengenalan Sistem Informasi. Yogyakarta: Andi Offset.

Khaidir dan Neri Susanti. 2015. Analisis Faktor-Faktor yang Mempengaruhi Kinerja Sistem Informasi Akuntansi Pada Bank Rakyat Indonesia Kantor Cabang Bengkulu.

Krismiaji. 2015. Sistem Informasi Akuntansi. Unit Penerbit, Yogyakarta.

Mulyadi. 2015. Sistem Informasi Akuntansi. Yogyakarta: Penerbit UUP AMP YKPN.

Puspitawati, Lilis dan Sri Dewi Anggadini. 2011. Sistem Informasi Akuntansi. Yogyakarta: Graha Ilmu.

Rahadi, Dedi Rianto. 2010. Manajemen Kinerja Sumber Daya Manusia. Malang: Tunggal Mandiri Publishing.

Rivaningrum, Ajeng dan Amir Mahmud. 2015. Faktor-Faktor yang Mempengaruhi Kinerja Sistem Informasi Akuntansi pada Rumah Sakit Saras Husada Purworejo. Accounting Analysis Journal [Online], Vol 4 No 2, 7 halaman. Tersedia: https://doi.org/10.15294/aaj.v 4i2.7811 [ 02 Maret 2019].

Romney, Marshall B. dan Paul John Steinbart. 2006. Sistem Informasi Akuntansi. Edisi Sembilan, Buku Satu, diterjemahkan: Deny Arnos Kwary dan Dewi Fitriasari. Salemba Empat, Jakarta.

Romney, Marshall B. dan Paul John Steinbart. 2015. Accounting Information Systems. Thirteenth Edition. New Jersey: Pearson Prentice Hall, Inc.

Sahusilawane, W. 2015. "Pengaruh Partisipasi Pemakai dan Dukungan Atasan Terhadap Kinerja Sistem Informasi Akuntansi pada Bank Umum Pemerintah”. Jurnal Organisasi dan Manajemen, Vol 10 No 1. Halaman. 37-43.

Sharma, R, P. 2003. The Contingent Effect of Management Support and Task Interpedence on Successful Information System Implementation. MIS Quarterly, Vol 7 No 4. Halaman 533.

Sugiyono, 2010. Metode Penelitian Kuantitatif, Kualitatif, dan R\&D. Bandung: Alfabeta

Sugiyono, 2017. Metode Penelitian Kuantitatif, Kualitatif dan R\&D. Bandung: Alfabeta.

Susanto, Azhar. 2017. Sistem Informasi Akuntansi. Bandung: Lingga Jaya.

Sutabri, Tata. 2014. Pengantar Teknologi Informasi. Yogyakarta: Andi. 